\title{
An Evaluation of the Double Torsion Technique
}

\author{
T.H. Becker ${ }^{1}$, T. J. Marrow ${ }^{2}$, R.B. Tait ${ }^{3}$ \\ ${ }^{1}$ Ph.D. student, University of Cape Town, visiting researcher at The University of \\ Manchester, Materials Performance Centre, A11, The Mill, Sackville street, Manchester, UK \\ M13 9PL
}

Email: thorsten.becker@uct.ac.za or thorsten.becker@manchester.ac.uk (corresponding author)

${ }^{2}$ Director of Materials Performance Centre, The University of Manchester, Manchester, UK

Email: james.marrow@manchester.ac.uk

${ }^{3}$ Professor in Mechanics of Solids, Department of Mechanical Engineering, University of Cape Town, Cape Town, South Africa

Email: robert.tait@uct.ac.za

\begin{abstract}
Double Torsion (DT) is a powerful testing technique for fracture mechanics characterization of brittle materials as, in principle, it provides a crack length independent test configuration. However, several corrections have been proposed to address reported scatter of experimental results from various laboratories. These correction factors address the validity of the DT configuration and its crack length independent stress intensity. Never the less, there seems to be no consensus in literature on the various corrections and the reason of reported scatter. This paper presents a critical review of the DT technique and its proposed corrections through an experimental analysis using the proposed corrections, a Finite Element model of the geometry and Digital Image Correlation to measure out-of-plane surface deformations. It focuses the validity of the constant stress intensity regime and the independence of crack length using Polymethylmethacrylate in a critical evaluation.
\end{abstract}

Assessment of three un-grooved specimen geometry configurations demonstrated the apparent regime of constant stress intensity, although a small but clear dependence of the stress intensity on crack length was observed in all specimen configurations. This dependence is attributable to significant load-point deflections and out-of plane deformations that are not accounted for in the DT analysis. Revisions of the proposed analysis methodologies show that a crack length independent specimen geometry can be achieved, however at the cost of accurate data. Reliable data can be achieved with DT testing configuration using an optimum specimen configurations.

Keywords: Double Torsion, review, PMMA, facture toughness, VK relationship, Digital Image Correlation (DIC), out-of-plane deflections. 


\section{NOMENCLATURE}

\begin{tabular}{|c|c|}
\hline$a$ & Crack length \\
\hline$A$ & Crack surface area \\
\hline$a_{i, f}$ & Initial or final crack length during load relaxation tests \\
\hline$a_{n}$ & Notch length \\
\hline$a_{\text {off }}$ & Crack offset from specimen symmetry line \\
\hline$\Delta a$ & Crack front extension \\
\hline$B_{A}$ & Compliance relationship slope determined analytically \\
\hline$B_{E}$ & Compliance relationship slope found experimentally \\
\hline$C$ & Compliance \\
\hline$c$ & Crack front inclination $(\Delta a / d)$ \\
\hline$d$ & Specimen thickness \\
\hline$D_{E}$ & Compliance relationship y-axis intercept found experimentally \\
\hline$d_{n}$ & Specimen thickness with notch \\
\hline$E$ & Young's modulus \\
\hline$G_{I}$ & Shear release rate energy (Mode I) \\
\hline$G_{I c}$ & Critical strain energy release rate \\
\hline$k$ & Chevalier's correction constant \\
\hline$K_{\text {eff }}$ & Effective stress intensity \\
\hline$K_{I}, K_{I I I}$ & Stress intensity factor for mode I and mode III respectively \\
\hline$K_{I c}$ & Fracture toughness (mode I) \\
\hline$L$ & Specimen length \\
\hline $\log (B)$ & Sub critical crack growth constant \\
\hline$m$ & Chevalier's correction constant \\
\hline$n$ & Sub critical crack growth index \\
\hline$r$ & Distance through specimen thickness ( $r=d$ at upper tensile surface) \\
\hline$P$ & Applied load \\
\hline$P_{c}$ & Critical applied load \\
\hline$P_{i, f}$ & Initial or final applied load during load relaxation tests \\
\hline$T$ & Time \\
\hline$V$ & Crack velocity \\
\hline$W$ & Specimen width \\
\hline$w_{m}$ & Moment arm / lever arm \\
\hline$w_{m}$ off & Offset or error in moment arm due to misalignment \\
\hline$y$ & Cross head displacement \\
\hline$\dot{y}$ & Cross head velocity \\
\hline$\alpha$ & Crack front angle \\
\hline$v$ & Poisson's ratio \\
\hline$\zeta$ & Ciccotti's correction function \\
\hline$\Phi$ & Crack velocity averaging value \\
\hline$\eta$ & Ciccotti's correction function \\
\hline$\Psi$ & Thickness correction factor \\
\hline$\mu$ & Shear Modulus \\
\hline
\end{tabular}




\section{INTRODUCTION}

The Double Torsion (DT) technique is a powerful testing configuration, which allows the investigation of fracture characteristics of highly brittle materials. One of the distinguishing features of this technique is that the stress intensity factor (SIF) is said to be independent of crack length. This feature is especially attractive as it enables the propagation of relatively long cracks in a highly controlled manner in exceptionally brittle materials, such as graphite for example [1]. Further, due to the way the DT specimen is loaded, the geometry allows for easy crack tip observations at a constant crack driving force, useful for fracture process zone observations in quasi-brittle materials $[1,2]$. The technique is also suitable for testing configurations where crack length measurements could be difficult to make, such as the evaluation of opaque and non-reflective materials, or in high temperature and controlled environments. Another advantage over other testing configurations, such as single edge notch bend (SENB) or compact tension (CT), is the ability to easily generate slow crack growth studies (the $V K$ relation between stress intensity factor $K$ and crack velocity $V$ during sub-critical crack growth).

The technique was first introduced by Outwater and Gerry [3] in the late 1960's and the main development of the DT technique may be attributed to Evans [4] and William and Evans [5] and several good reviews are available in literature $[6,7]$. The specimen configuration essentially comprises of a rectangular thin beam supported in four point bend configuration at one end where the crack propagates through the specimen's length. A schematic diagram of the DT specimen is shown in Figure 1, where: $a$ is the crack length, $a_{n}$ the notch length, $w_{m}$ the applied moment arm with load $P$ and deflection $y$ at the load points. The specimen has dimensions: length $L$, width $W$ and thickness $d$. Grooves, aligned along the specimen length, are sometimes used to constrain the crack path. These, however, can cause substantial stress concentrations near the crack tip [7-9], whereby with careful alignment of the test specimen in combination with a high-quality fixture the need for these grooves can be eliminated $[7,9]$.

The cornerstone of the DT methodology is the aforementioned feature of a crack length independent SIF. According to Williams and Evans [5] the strain energy release rate $G$, and hence an equivalent $\operatorname{SIF}$ (using $K=\sqrt{E G}$ ), is given by

$$
G_{I}=-\frac{\mathrm{d} U}{\mathrm{~d} A}=\frac{P^{2}}{2 d} \frac{\mathrm{d} C}{\mathrm{~d} a}=\frac{w_{m}^{2} P^{2}}{2 \mu W d^{4} \psi}
$$


where $U$ is the total strain energy, $A$ the crack extension surface area, $P$ the applied load, $C$ the compliance of the specimen, $\mu$ the shear modulus and $\psi$ a thickness correction given as a function of $W / d^{4}$.

The above expression, Eq. 1 is entirely crack length independent and has been derived from the following assumptions.

- The specimen has two symmetrical, independent halves, subjected only to torsional loading due to load $P$ with moment arm $w_{m}$. The crack separates the two halves.

- The specimen is only subjected to small torsional deformations and the unbroken ligament is assumed to remain rigid.

- The crack front or crack profile is assumed to remain constant throughout crack extension.

- Fracture occurs in pure mode I.

The practical importance of these approximations, made necessary by the analytical approach, is still unknown and several concerns around the actual crack length independence arose independently from several different investigations [8, 10-17]. It has been shown that the stress intensity factor could be a function of the crack length, indicated by a shift in the VK relationship data [11-16] (discussed in section 4.5). As a result, various corrections have been incorporated into Evan's conventional methodology. These include Leevers et al's large deflection correction [18], Chevalier et al's crack length dependent SIF correction [12] and Ciccotti et al's finite element based correction to account for crack length dependencies in VK relationship data $[19,20]$. These corrections, which are based on analytical, empirical, or FE derivation aim to force the inherent crack length independent geometry. None-the-less, there seems to be no consensus in literature on the various corrections and the reason of reported scatter. It follows that although the DT technique offers significant advantages due to its ability to propagate cracks controllably, there remains a concern about its inherent crack length independence and other aspects such as the optimal dimensions and test procedures.

Given that question remains regarding the applicability of the crack length independent SIF and the technique is yet to be standardised, this paper aims to critically assess the DT technique and its correction factors. It intends to address the proposed corrections with respect to the crack length independent SIF and investigating the importance of the 
approximations made with respect to the analytical derivation. Considering that alignment is critical in the DT configuration, the effects of misalignment are also investigated. The evaluation is made via an experimental procedure of the various proposed corrections (Evans [4], Leevers et al. [18], Chevalier et al. [12] and Ciccotti at al. [19, 20]), a finite element (FE) analysis of the full DT specimen geometry accounting for crack surface interaction, and measurement of the out-of-plane deflections of loaded samples by digital image correlation (DIC).

\section{ANALYTICAL ANALYSIS AND PROPOSED CORRECTIONS}

The DT specimen comprises a rectangular plate which is loaded in a four point bending configuration at one end across a starter notch (Figure 1). The specimen can essentially be considered as two halves around the cracked portion, which deform independently. Subjected only to small torsional deformations, the stiffness of each half is a function of its cross-section and length. As a result, the stiffness of each half and thus the specimen is only function of the specimen's crack length. If assumed that the unbroken ligament remains completely rigid, a linear compliance relationship is obtained [4]

$$
C(a)=\frac{y}{P}=B_{A} a=\frac{3 w_{m}^{2}}{W d^{3} \mu} a
$$

The crack front or crack profile is assumed as straight and perpendicular to the specimen plane throughout crack extension. It is worth mentioning that this linear compliance relationship provides the aforementioned crack length independent SIF. It has been shown experimentally, that the compliance is indeed linear, however a scaling constant is included to account for a shift in the compliance slope $[4,5,14]$.

$$
C(a)=\frac{y}{P}=B_{E} a+D_{E}
$$

where, $B_{E}$ is the slope and $D_{E}$ is the $y$-axis intercept. The experimental compliance has been shown to be in agreement with the analytical compliance [14], in which case $D_{E}$ is assumed to be zero and

$$
B_{E} \approx 3 w_{m}^{2} / W d^{3} \mu=B_{A}
$$


The crack profile in DT setup is curvilinear and therefore, a crack front inclination is defined by $c=\Delta a$, where $\Delta a$ is crack extension difference between the upper and lower surface (Figure 1). It has been contended that the crack front geometry is material specific [21] and dependent on the slow crack growth exponent [22]. However, it has also been shown that the shape of the crack front does not vary with crack length and therefore the assumption of constant crack extension is still valid [5, 23].

\subsection{Evans" "conventional" methodology}

Eq. 1 provides the elastic strain energy release rate for the DT geometry, obtained using Irwin's expression for Linear Elastic Fracture Mechanics (LEFM) in mode I rupture. For this the crack front shape is assumed to remain constant through crack propagation, so that $d A=$ $d \cdot d a$. Since LEFM conditions apply, $G_{I}$ may be related to the more commonly used SIF by $K_{I}=\sqrt{\left(E^{\prime} G\right)}$ where, $E^{\prime}=E /\left(1-v^{2}\right)$ and $E^{\prime}=E$ in plane strain and stress conditions respectively ( $E$ and $v$ being the Young's Modulus and Poisson's ratio). The expression for $K_{I}$ is given in Eq. 5 for plane strain conditions

$$
K_{I}^{E}(P)=P w_{m} \sqrt{\frac{3}{W d^{4}(1-v) \psi(d, W)}}
$$

where, $\mu$ is the shear modulus and $\psi(d, W)$ a thickness correction factor, derived by Fuller [14], to account for the interaction between the crack surfaces.

$$
\psi(\tau)=1-0.6302 \tau+1.20 \tau e^{-\pi / \tau}
$$

where $\tau(d, W)=(2 d / W)$. The validity of the thickness criterion was confirmed using tests of a glass ceramic [24]. The SIF given by Eq. 5 is a function of the applied load, the test specimen geometry and Poisson's ratio but independent of crack length. It is this characteristic that makes double-torsion testing most attractive. The independence of the SIF however, is limited to a range of crack lengths due to edge effects, which can lead to a deviation from the linear crack length-compliance relationship. Generally the middle half to a third of the specimen is regarded as crack length independent [7]. The critical strain release rate energy $G_{I c}$, or fracture toughness, $K_{I c}$, may be calculated by substituting $P$ with the critical load $P_{c}$ into Eq. 5. 


\subsubsection{Crack growth analysis}

One of the most important characteristics of the DT methodology is the ability to measure the rate of slow crack growth without having to monitor the crack length on a continuous basis. For this, the sub-critical quasi-static crack growth or materials experiencing environmentassisted cracking is defined by the relationship

$$
V=B K_{I}^{n}
$$

this may be reformulated as

$$
\log (V)=n \log \left(K_{I}\right)+\log (B)
$$

where, $\log (B)$ is a constant and $n$ is the subcritical crack growth index. $n$ may be evaluated by the commonly used load relaxation technique or the constant displacement technique.

According to the load relaxation technique, a pre-cracked specimen is loaded to just below the expected fracture load (i.e. 0.9 to $0.95 P_{c}$ ) and the crosshead displacement is fixed (noted as subscript ${ }_{y}$ ). The increase in test specimen compliance with crack growth relaxes the load with time and can be described by differentiating Eq. 3 with respect to time

$$
\frac{\mathrm{d} y}{\mathrm{~d} t}=\left(B_{E} a+D_{E}\right) \frac{\mathrm{d} P}{\mathrm{~d} t}+P B_{E} \frac{\mathrm{d} a}{\mathrm{~d} t}
$$

Since the DT geometry enjoys a linear compliance and the crosshead is arrested during a load relaxation procedure, the initial and final loads may be equated

$$
P_{i}\left(B_{E} a_{i}+D_{E}\right)=P_{f}\left(B_{E} a_{f}+D_{E}\right)
$$

where subscripts ' $i$ ' and ' $f$ ' denote the initial and final during a load relaxation procedure. Hence, by setting Eq. 9 equal to zero and rearranging it with Equation 10 an expression for the crack velocity $V$ is given as

$$
V_{y}(P, t) \equiv\left(\frac{\delta a}{\delta t}\right)_{y}=\phi \frac{-P_{i, f}}{P^{2}}\left(a_{i, f}+\frac{D_{E}}{B_{E}}\right)\left(\frac{\delta P}{\delta t}\right)_{y}
$$

where $\phi$ is a crack velocity averaging factor derived by Pollet and Burns [23], which is required since the crack velocity varies along the crack front's curved profile. 


$$
\phi(\alpha, d)=\left(\frac{1}{d} \int_{0}^{d}(\sin [\alpha(x)])^{\frac{1}{n}}\right)^{n}
$$

where $n$ is the slow crack growth exponent and $\alpha$ is the function of the crack front angle to the specimen's surface. Other curved crack front corrections have been derived [4, 25, 26]. However Pollet and Burns' averaging process is more widely accepted in the literature. Fuller assumed that the ratio $D_{E} / B_{E}$, used in Eq. 11, may be excluded if significantly less than $a_{i, f}$.

Another technique for slow crack growth determination using the DT technique includes the constant displacement rate technique. The crosshead is moved at a constant rate and the load value is allowed to reach a plateau (with $\mathrm{dP} / \mathrm{dt} \sim 0$ ), where the increase in load from crosshead movement is balanced by relaxation of the test specimen load due to crack growth. If the plateau load is given by $P_{c}$, Eq. 9 reduces to

$$
V_{P}(\dot{y}, t)=\phi \frac{1}{P_{c} B_{E}}\left(\frac{\delta y}{\delta t}\right)_{p}=\phi \frac{\dot{y}_{p}}{P_{c} B_{E}}
$$

\subsection{Leevers' corrections}

Leevers' proposed a correction for the errors caused by large deflections at the load points [18]. The large deflection correction (LDC) corrects for the decrease in moment $\left(w_{m}\right)$ due to the rotation of the loading contact points on the specimen's surface as shown in Figure 2. This is defined as $w_{m}{ }^{L D C}$ in this paper. Earlier work done by Hine et al. [27] provided a different LDC, although this was since shown to generally under estimate the error [18].

\subsection{Chevaliers' correction}

Chevalier and co-workers [12] reported a crack length dependence of the SIF in studies of zirconia and alumina. They attributed a minor crack length dependence due to deflections of the unbroken ligament and then proposed a correction for load relaxation tests that depended on the sample dimensions and loading configuration. The crack length independent SIF was then

$$
K_{I}^{c h}(P, a)=K_{I}^{E}(P)\left(\frac{a}{a_{n}}\right)^{\frac{m}{k}}
$$


where, $m$ and $k$ are constants for the test specimen geometry and material considered. The crack length was estimated during load relaxation tests as

$$
a^{c h}(P)=\frac{\left(\frac{P_{i, f}\left(B_{E} a_{i, f}+D_{E}\right)}{P}\right)-D_{E}}{B_{E}}
$$

derived from the compliance relationship. Their correction results in a shift of the $V K$ curve and an increase of the stress corrosion index $n$ [28]. Crack velocities are found using Eq. 11 or Eq. 13.

\subsection{Ciccotti's correction}

Ciccotti and co-workers [19, 20, 29] performed a three dimensional finite element (FE) stress analysis on a symmetric DT geometry model, including contact between the crack faces. They concluded that appreciable deviations (as much as 40\%) occurred from the classical analytical solution for strain energy release rate, and that these were due to non-linearity of the compliance relationship. They provided two correction factors $\varphi(a)$ and $\xi(a)$ for calculation of $K_{I}$ and $V$ to account for experimental variables such as crack shape, groove width and depth, notch length and test specimen geometry

$$
\begin{aligned}
& C^{C i}(a)=\varphi(a) B_{A} a \\
& K_{I}^{C i}(P, a)=K_{I}^{E}(P) \sqrt{\varphi(a)} \\
& V^{C i}(P, t, a)=-\phi \frac{\xi\left(a_{i, f}\right)}{\varphi(a)} \frac{a_{i, f} P_{i, f}}{P^{2}}\left(\frac{d P}{d t}\right)_{y}
\end{aligned}
$$

Both correction factors are a function of crack length, which may be estimated by

$$
a^{C i}(P)=C^{-1}\left(\frac{C\left(a_{i, f}\right) P_{i, f}}{P}\right)
$$

The correction factors were derived from FE models with five different crack lengths for three different specimen geometries. The functions for these correction factors were then obtained by a 3rd order polynomial fit to these five data. It is important to note that the recorded values are conditioned by the sample geometry. In cases where the sample geometry differs, linear interpolation is used. Examples were published by the authors [20]. 


\section{EVALUATION PROCEDURE}

This evaluation aims to examine the aforementioned assumptions which the DT methodology is based upon to achieve a crack length independent SIF. To do this, the evaluation consists of three parts:

- An experimental evaluation analysed using Evans' methodology and the corrections proposed by Leevers' Chevalier and Ciccotti using three specimen configurations.

- an FE simulation of the full specimen geometry, which includes crack surfaces interaction, a realistic loading configuration and an assessment of misalignment.

- DIC observations to measure the out-of-plane deflections of the unbroken ligament.

\subsection{Experimental Evaluation}

Compliance tests, fracture toughness tests and $V K$ investigations were undertaken using Polymethylmethacrylate (PMMA) specimens. PMMA is a clear, homogenous, isotropic brittle material that allows for easy observation of the crack tip. The material properties of PMMA were taken as $\mu=1.4 \mathrm{GPa}$ for the shear modulus and $E=3.7 \mathrm{GPa}$ for the Young's modulus [30].

Three different specimen geometry ratios were considered, normalised with respect to the width and notated as a length to width to thickness ratio $(\mathrm{L}: \mathrm{W}: \mathrm{d})$. These are summarised in Table 1. These were chosen from the dimensions previously used by Chevalier [12], Tait [7] and Ciccotti $[19,29]$. Starter notches were machined to lengths of $a_{n}=20 \mathrm{~mm}$ or $40 \mathrm{~mm}$ with a crack front inclination of $c=4$ to closest resemble the curved crack front and to ensure symmetrical crack initiation. Specimens were pre-cracked to length $a_{p}$ to achieve a sharp fully formed curved crack front, unless the aim of the experiment dictated otherwise.

A DT fixture was constructed to reliably achieve symmetrical crack growth. This was found to eliminate the need for side grooves to control crack growth. Non-symmetrical crack propagation within the defined crack length independent SIF shown in Figure 1, (i.e. deviation of the crack path from the centreline of the specimen) was recorded as $a_{\text {off. }}$. The crack length independent SIF region was regarded as $0.25<a / L<0.75$, according to Tait et al's recommendations [7]. 
The experimental tests were carried out in the Materials laboratory at the University of Cape Town at room temperature using a Zwick tensile/compressive servo controlled, screw driven testing machine with a $5 \mathrm{kN}$ load cell. Crack length measurements, to an accuracy of 0.2 mm, used a Nikon SMZ10 microscope mounted on a sliding mechanism. Specimens were pre-cracked to length $a_{p}$ at a low cross-head speed ( $>0.1 \mathrm{~mm} / \mathrm{min}$, manually controlled), until a fully formed crack front was established. Load, displacement and time were recorded continuously. Compliance curves were thus determined according to Eq. 2, 3 and 16 for the analytical, experimental and Ciccotti's compliance, respectively. SIF values were then calculated using Eq. 4, Eq. 14 and Eq. 17 for Evans', Chevalier's and Ciccotti's methodologies respectively. Fracture toughness tests were conducted at a fast cross head speed of $\dot{y}=4 \mathrm{~mm} / \mathrm{min}$ sufficient to ensure unstable fracture [14] where the critical load $P_{c}$ was used to calculate $K_{I c}$. VK data was determined using load relaxation and constant displacement rate tests for comparative purposes using Eq. 11 and Eq. 13 for Evans', Leevers' and Chevalier's methodologies and Eq. 18 for Ciccotti's method respectively.

\subsection{Finite Element Model}

A FE model of the DT geometry was constructed using ABAQUS/standard V. 6.7 [31]. The FE model represented the full DT geometry and loading configuration under constant displacement loading (Figure 3a). Most of earlier FE models assumed a symmetrical DT geometry, in which the model only described half of the specimen, loaded in pure torsion [29, 32]. This was due to computational limitations that no longer apply. In those analyse the cracks were treated as discontinuities with smooth and frictionless surfaces where mode I loading was assumed. However, if the crack surfaces offer frictional resistance due to sliding in the DT configuration, a symmetrical assumption may lead to error. The modelling of the whole specimen provides a more realistic configuration that can analyse the effects of load misalignment and crack opening modes. Contact between the crack surfaces was defined by the Coulomb friction law for rough surfaces, with an assumed friction coefficient of 0.5 [3335].

A concentrated mesh with collapsed elements at the crack tip was used (Figure $3 \mathrm{a}$ and $\mathrm{b}$ ). This allows a better description of the strain field near the crack tip and has been validated against analytical solutions [32]. Mode I and III stress intensity factors along the crack front were directly calculated by ABAQUS using the contour integral method [36]. Additionally, the out-of-plane deflections of the ligament and the compliance relationship were extracted. 
The rotational loading was applied as a displacement to an analytically rigid body, tied to the outer edge of the DT geometry (Figure 3a). This gave a four point bending loading configuration with a moment arm length $w_{m}$. This way, the torsional load configuration incorporating the fixed support points (as a 4 point bend configuration) could be modelled excluding any point load effects. 20 different specimen configurations were modelled. These consisted of two specimen geometry ratios, each with two different crack front inclinations, namely $c=0$ and $c=4$, at five crack lengths of $37.5,56.25,75,93.75$ and 112.5 $\mathrm{mm}$ respectively. The crack front inclinations were limited to a maximum inclination of $c=4$ so as not to distort elements internal angles below $10^{\circ}$.

Since non-grooved specimen geometries were considered, the effect of specimen misalignment was modelled as a percentage difference in the applied moment on each specimen halves torsion arm. This was believed to be an accurate representation of misalignment since misalignment of the specimen in the loading jig would result in a shift of the loading points and would cause an imbalance in the applied moment.

The models contained a total number of 7468 and 9465 quadratic brick elements for the geometries with crack front $c=0$ and $c=4$ respectively. PMMA was defined as a linear elastic material with the properties stated previously.

\subsection{Digital Image Correlation}

DIC allows full field displacement measurements to be obtained throughout the deformation of material in two or three dimensions, depending on the camera system [37]. DIC operates through the discretisation of an image into multiple interrogation windows, which are correlated with the same features in the following images. Displacement vectors are obtained for the change in position of each interrogation window, allowing strain distributions across the full image to be calculated [38]. DIC allows sub-pixel displacement measurements [39]. The technique is independent of scale, with the quality of results depending on the image capture camera, particularly its bit depth and resolution.

The Digital image correlation technique was employed at the University of Manchester to analyse the out-of-plane deformation during cracking of PMMA DT specimens. The system used two Davis ${ }^{\circledR}$ Imager Pro X 4 Megapixel cameras and LA Vision DaVis software ver.7.2 
[40]. The two camera analysis was used as the DT specimen experiences some out-of-plane deflections. These cause errors in single camera observations, and it was necessary to measure the in-plane displacements accurately [41]. The displacement vector accuracy is dependent on the interrogation window size, and best results were obtained by an interrogation window size of $128 \times 128$ pixel window size with $75 \%$ overlap, which allowed for around 0.01 pixels accuracy [40]. The large overlap provided a sufficient number of displacement vectors. One pixel was approximately $50 \mu \mathrm{m}$, for an imaged area of $100 \times 100$ $\mathrm{mm}$. The DT specimens were tested at $4 \mathrm{~mm} / \mathrm{min}$ constant displacement rate with DIC frequency of $1 \mathrm{~Hz}$.

\section{RESULTS AND OBSERVATIONS}

52 PMMA specimens were tested in the experimental evaluation. This included 20 fracture toughness tests, $20 \mathrm{VK}$ investigations (limited to a maximum of three relaxations per specimen), nine compliance tests and three DIC observations. Their respective dimensions are reported in Table 1.

\subsection{Correction Factors}

Table 2 shows all the calculated aforementioned correction factors for the three specimen considered specimen geometries, determined according their specified methodologies. The LDC correction was found to be essential, as large deflections at the load points result in a significant decrease of the moment arm $w_{m}$. An example is the decrease from $16 \mathrm{~mm}$ to 14.5 $\mathrm{mm}$ for the $4.0 \mathrm{~mm}$ thick specimen configuration. Failure to correcting for these large deflections can result in an error in $K_{I}$ of up to $25 \%$ (Figure 4). The crack front inclination was established at $c=\Delta a / d \approx 5$, where the crack tip shape, once established, was found to remain constant with crack length.

\subsection{Compliance Relationship}

Table 3 summarises the linear compliance relationships found experimentally, analytically and through the FE model respectively. A good average correlation was found between these relationships with less than $2 \%$ difference. It is worth mention, that the assumption that $D_{E} / B_{E}$ in Eq. 11 is significantly less than $a_{i, f}$ (as commonly assumed), does not hold true here, as $D_{E} / B_{E}$ has a magnitude of approximately $20 \mathrm{~mm}$ compared to $a_{i, f}$, which ranged from 
37.5 to $112.5 \mathrm{~mm}$. This becomes significant for the VK data plots and thus requires experientially determined compliance in order to reduce a significant shift in VK relationship data.

Since the crack length independence of the DT technique is dependent in the linearity of the compliance relationship, it provides a tool for assessing the aforementioned assumptions. This is shown in Figure 5, which compares the compliance relationships obtained from the experimental, analytical, Ciccotti's correction and the FE model for the $2.7 \mathrm{~W}: \mathrm{W}: 0.11 \mathrm{~W}$ configuration. The experimentally and FE determined compliance show similar behaviour with a slight deviation from linearity at larger crack lengths. This observation was found in all specimen configurations (most exaggerated with the thicker $2.7 \mathrm{~W}: \mathrm{W}: 0.11 \mathrm{~W}$ geometry) and thus suggests a crack length dependent geometry. Ciccotti's corrected compliance, which aims to provide a crack length independent geometry, did not agree with experimental data.

The non linearity of the compliance has been attributed to the deformation of the unbroken ligament $[12,28]$, which introduces error in the prediction of torsional deformation of the broken ligaments. The observation of surface displacements obtained by DIC (2.7W : $W$ : $0.11 \mathrm{~W}$ geometry.

Figure 6) confirms these out-of-plane deformations. $2.7 \mathrm{~W}: W: 0.11 \mathrm{~W}$ geometry.

Figure 6 additionally confirms, in agreement with the FE model, that these deformations do not remain constant with crack extension thus contributing to the overall non linearity of the compliance data. This effect again is amplified by the thicker specimen configuration. This is further discussed in section 5 .

\subsection{Crack length independence}

To further investigate the effect of the non-linear compliance, the various proposed corrections were compared by plotting the SIF, calculated according their methodologies, versus the crack length. This is shown in Figure 7 for the $2.7 \mathrm{~W}: \mathrm{W}: 0.11 \mathrm{~W}$ configuration. Both Chevalier's and Ciccotti's corrections achieved the crack length independent SIF (i.e. a constant SIF), however, a gradual decrease in the SIF with increasing crack length was observed when using Evan's "conventional" methodology with or without the LDC. These findings are in agreement with the FE analysis (Figure 8), where a clear crack length dependence on the SIF was found, especially for the thicker specimen configuration. 
Additional factors which can contribute to the overall validly of a crack length independent geometry are the testing procedures. Similar to Figure 7, Figure 9 illustrates the variation of the SIF with crack length for specimens with various crack propagations for the $3 W: W$ : $0.08 \mathrm{~W}$ configuration. Investigated were the effects of a fully pre- and symmetrically cracked specimen, versus a non-pre-cracked or non-symmetrically cracked, or both specimens. Also, Figure 9 clearly shows the effect of misalignment and the pre-cracking procedure. The observations were the following:

- During the pre-cracking stage the curvilinear crack front develops. At this point the rate of crack extension area $d A$ is not constant, but increases until a fully formed crack front has developed. This has been confirmed by Ricco et al. [42] who compared the load vs. time relationship for PMMA specimens with the corresponding crack speed vs. time recording, obtained from a video recording. Hence, the assumption made in Eq. 1 do not hold valid and it follows that during the pre-cracking phase artificially high SIF's are obtained that lead to erroneous fracture toughness readings or unreliable VK relationship data.

- During non-symmetrical or "skew" crack propagation the opposite can be observed. The calculated SIF decreases with increase in crack deviation $\left(a_{o f f}\right)$. The argument follows that due to the non-symmetrical crack propagation the torsional stiffness changes in each half. The ability to support the same torsional load, in the case of the reduced specimen half, reduces and hence the ability to support the crack propagation weakens. This argument is in agreement with Salem et al. [43] who tested non-symmetrical specimens and concluded that specimen symmetry should be within $1 \%$. This is further discussed in Section 4.7.

There is an important observation to note; since the measure of fracture toughness is only dependent on the peak load and crack deviation is always small at short crack lengths (provided the starter notch is machined on the symmetry line), the consequence of misaligned specimen in the fracture toughness is small. The effect of misalignment, however, becomes adverse in VK investigations since continues SIF is required over larger crack extensions.

The FE analysis provides additional insight into the SIF's independence with crack length. Visual inspections have shown that the crack tip front remains similar in shape over the 
middle section of the specimen. The SIF distributions along the specimen depth for two considered crack lengths, namely $37.5 \mathrm{~mm}$ and $112.5 \mathrm{~mm}$ are shown in Figure 10. Since an angled crack front was assumed $(c=4)$, the SIF profile is not representative of a real crack front, which is curved. However, it can provide insight into any variations of the profile with crack length. Observed in Figure 10 was a small overall decrease between the two profile curves (with increasing crack length). This is in agreement with the experimental observations where a similar trend was observed.

One of the difficulties associated with the double torsion technique is whether it is appropriate to describe the mode of failure as mode I. Fuller [14] believed that the fracture mode is indeed mode I since the loading configuration and specimen geometry are symmetrical about the crack plane. The contention that there is a mode III (shear) component appears to depend on the relative amount of axial to through thickness crack driving force [14]. The FE analysis conducted in this paper shows that indeed some mixed mode fracture is present suggesting a mixed mode loading configuration as shown in Figure 10. The analysis shows a mixed mode facture is less than $2 \%$ and no thickness dependence could be established between the two considered geometry configurations. The error induced by the assumption of pure mode I failure seem negligible considering experimental error and comparative results with other techniques show that the mode I is in fact applicable for materials which have much larger $\mathrm{K}_{\mathrm{I}}$ than $\mathrm{K}_{\mathrm{III}}$ values $[5,14]$.

\subsection{Fracture Toughness}

Table 4 shows the results of 20 fracture toughness tests, which were undertaken at a constant crosshead displacement of $\dot{y}=4 \mathrm{~mm} / \mathrm{min}$. Excellent agreement was found between the toughness values obtained from the Evans methodology and the FE model. Chevalier's and Ciccotti's corrections are strictly speaking derived for load relaxation tests, however, since the fracture toughness is obtained as a maximum, the use of their correction methodologies is possible. In agreement with Madjoubi [28], Chevalier's correction generally gives an overestimation in SIF due to the exponent value. Ciccotti's results on the other hand show a decrease in SIF, which may be attributed to the fact that specimen ratio of $2.7 \mathrm{~W}: \mathrm{W}: 0.117 \mathrm{~W}$ was not entirely satisfied. No dependence on specimen geometry ratio was observed within each analysis method. 


\subsubsection{Direct calculation of Fracture Toughness}

To validate the aforementioned calculated fracture toughness, an alternate approach was utilised, which directly calculates the fracture toughness using the Irwin relationship and specimen compliance. This method is similar to Albuquerque and Rodrigues determination of R-curves using the DT geometry [44] and is based on the assumption of linear elastic fracture mechanics (LEFM).

The direct method makes use of consecutive loading and unloading curves, generated by loading and unloading the specimen with some crack propagation. The compliance $C_{l}$ at crack length $a_{1}$ was calculated as the slope of the loading curve. This procedure was repeated for a second cycle, $C_{2}$ and $a_{2}$. A schematic is shown in Figure 11. $G_{I c}$ and hence $K_{I c}$ were calculated using the following equation

$$
G_{I}^{P}=\frac{P^{2}}{2}\left(\frac{\mathrm{d} C}{\mathrm{~d} A}\right) \equiv \frac{1}{2 d} P^{2}\left(\frac{C_{2}-C_{1}}{a_{2}-a_{1}}\right)
$$

The advantage is that this methodology does not assume a linear compliance relationship, and hence the SIF is calculated directly from the energy required to propagate the crack. Since this methodology requires crack length measurement to be taken at each loading cycle, it cannot be used for load relaxation tests to investigate slow crack growth behaviour. However, it may be of use for constant rate of displacement tests, where the plateau load at a set displacement rate maybe be used to verify points on the load relaxation technique obtained VK curve. Excellent agreement was found between Evans, the alternate methodology and the FE model which is also documented in Table 4.

\subsection{VK Relationship}

Figure 12 shows the VK plots obtained using Evans' method, Chevalier's and Ciccotti's correction respectively. The results are summarised in

Table 5. The reproducibility of VK relationship data using Evens "conventional" methodology, where several relaxation tests were conducted on a single specimen, shows a transverse shift in the VK data. This effect has been discussed before [7, 8, 12, 29, 44] and is believed to be a consequence of a non - crack length independent SIF. Figure 13 compares the relative scatter of VK relationship data as a function the y-axis intercept $\log (B)$ deviation (which quantifies the shift in VK data lines) and specimen configuration. Chevalier's correction achieved the best reproducibility for all configurations, where Evans method 
showed an increased error with the thicker specimen configuration. Ciccotti's correction could only be utilised for the $2.7 \mathrm{~W}: \mathrm{W}: 0.11 \mathrm{~W}$ geometry with relatively good reproducibility.

\subsection{Specimen Geometry}

The double-torsion specimen can be regarded as a thin plate with typically the proportions of a microscope slide [7]. However, there do not appear to be standard specimen proportions. A review of DT specimen sizes presented by Tait et al. showed that the relative proportions are popularly three times the width and a thickness between $1 / 6$ and 1/15 of the specimen width [7]. They recommended that specimen proportions should be of the order of $3 W: W: 0.12$ to $0.08 \mathrm{~W}$. The use of longer specimens $(L>3 W)$ reduces the edge effects however it can be difficult to achieve symmetrical crack propagation if un-grooved specimens are used. This work has shown that side grooves are not necessary and symmetrical cracking can be achieved by careful alignment.

It has been revealed in this analysis that the geometry configuration can influence the validity of the crack length independent SIF. The general observed trend was a decrease in the SIF with increasing crack length consistent with a smaller change of out-of-plane deformations.

Best repeatable data was achieved with the thinner $3 W: W: 0.08 W$ configuration, which showed least SIF deviations with increasing crack length. The thicker and shorted configuration $(2.7 \mathrm{~W}: \mathrm{W}: 0.11 \mathrm{~W})$ showed a poorer constant SIF resulting in reduced VK relationship data repeatability. It appears applicable to mention that if plane strain contentions are assumed the plane strain thickness condition should be considered when sizing specimens.

\subsection{Alignment}

Poor crack plane alignment relative to the specimen symmetry line causes the crack to curve to one side rather than extending along the specimen centreline. The effect of this on the SIF's crack length independency was shown in Figure 9, where poor alignment results in lowered SIF readings.

Additionally, considerable variations in $D_{E}$ (the compliance y-axis intercept) were attributed to the symmetry of crack growth. An experimentally determined relationship between $D_{E}$ and $a_{\text {off }}$ (Figure 14) was established. From this a 95\% confidence in $D_{E}$ was established when $a_{\text {off }}$ is less than $1 / 8 \mathrm{~W}$. The shift of the compliance curve indicates a more compliant specimen 
configuration with increasing crack offset. This can be attributed the reduced stiffness of the broken specimen ligament due to the reduced in torsional load carrying capability. Values of $B_{E}$ and $D_{E}$ were compared to $a_{n}, a_{p}, a_{0}, a_{o f f}$ and $d$, where no further relations between $D_{E}$ or $B_{E}$ could be established

There is however an additional consideration that contributes to the way fracture occurs in a misaligned specimen. Figure 15 represents the effect of misalignment on the DT geometry with respect to the calculated SIF's from the FE model. Shown is the effect of mode III contribution to fracture with increasing misalignment. A misaligned specimen results in significant contributions of mode III fracture of up to $20 \%$ mode III in severely misaligned specimen configuration. With the aforementioned crack path offset threshold of $a_{\text {off }}=1 / 8 \mathrm{~W}$, it may be argued that an equivalent imbalanced load configuration has mixed mode fracture contribution of less than $6 \% K_{I I I}$.

\section{DISCUSSION}

This evaluation of the DT technique used an experimental, a full 3D FE model and digital Image correlation to assess the underlying assumptions that make the testing geometry crack length independent. A small but clear dependence of SIF on crack length was shown for all specimen configurations, especially for the thicker $2.7 \mathrm{~W}: \mathrm{W}: 0.11 \mathrm{~W}$ geometry. It follows that the geometry is not entirely crack length independent, validating the need for a correction if a crack length independent geometry indeed is required. The evaluation has shown that this can result in scatter of fracture toughness data and will cause non-reproducibility of VK relationship data.

These discrepancies can be attributed to marked non-linearity of the assumed linear compliance relationship. The assumptions that only the torisonal deformations of the broken ligament halves contribute to the compliance does not hold. DIC showed, in agreement with the FE model, that the assumed rigid unbroken ligament does deform considerably. Further, it was shown that this deformation does not remain constant, but increases with increasing crack length, thus resulting in a crack length dependency. Additionally, large deflections at the loading points result in added non-linearity as lever arm length decreases with increasing deformation. 
There is an interesting point to consider though. The deformations of the unbroken ligament have shown opposite effects on the compliance relationship to those of large deflections at the load points. The changes in the loading configuration due to large deflections at the load points result in a continuously decreasing compliance and the deformations of the un-cracked ligament result in a continuously increasing compliance. This makes the DT configuration complex and it may well be that both the large deflections at the load points and the deformation of the unbroken ligament, in some cases, cancel to form a linear compliance and a truly crack length independent system. Indeed, some investigators have obtained repeatable data with Evans' conventional method using a thin long specimen with a $3 W: W: 0.8 W$ configuration. This also further suggests that the validity of the crack length independent DT technique thus depends on the loading configuration, the specimen geometry and material stiffness.

The various corrections established in the literature are intended to account for these effects. Both Chevalier's and Ciccotti's corrections achieve a crack length independent specimen by correcting for the non-linear compliance. Chevalier's adjustment constants $m$ and $k$ are geometry specific, where a clear dependence of $m$ on the specimen thickness was established. According to their method, thinner specimens require less correction, with almost negligible correction for the specimen with dimension ratio $3 W: W: 0.08 W$. Ciccotti's work shows a great deal of attention to geometrical factors such as side grooves and starter notches, however, no variations in the thickness parameter were modelled.

\section{CONCLUSIONS}

- The evaluation of the DT technique using a 3D FE model has shown a small but clear dependence of the SIF on crack length for all specimen configurations. It has been shown that the validity of the common assumption of crack length independence is dependent on the loading configuration, the specimen geometry and material.

- Significant deflections at the loading points and the deformation of the unbroken ligament were measured using 3D Digital Image Correlation system. These result in a non-linear compliance relationship that causes the SIF to become crack length dependent. 
- The corrections proposed by Chevalier and Ciccotti achieved a crack length independent configuration, which enables reproducible fracture toughness and VK relationship data to be obtained for various specimen geometries. However, it was found that Chevaliers' correction overestimates and Ciccotti underestimates the calculated SIF by up to $10 \%$ in the geometries studied.

- Evans' conventional methodology with a large deflection correction can obtain valid fracture toughness and VK relationship data in some geometries; For example, ungrooved DT specimens with dimensions resembling $3 W: W: 0.08 W$. The middle half of the specimen's achieves an almost crack length independent regime (within 2\%), provided the crack tip remains within $a_{o f f}<1 / 8 \mathrm{~W}$ of the centreline for VK investigation.

- The DT methodology is a unique testing methodology which allows for the characterisation of the fracture characteristics of highly brittle materials and the authors believe that efforts should be focused on the standardization of this test method. It would prove useful to establish relationships between approximate material properties and specimen dimensions.

\section{REFERENCES}

1. Becker, T.H., R.B. Tait, and T.J. Marrow, Damage, Crack Growth and Fracture Characteristics of Nuclear Grade Graphite using the Double Torsion Technique. in preperation, 2010.

2. Tait, R.B. and G.G. Garrett, In situ double torsion fracture studies of cement mortar and cement paste inside a scanning electron microscope. Cement and Concrete Research, 1986. 16(2): p. 143-155.

3. Outwater, J.O. and D.J. Gerry, On the Fracture Energy, Rehealing Velocity and Refracture Energy of Cast Epoxy Resin. The Journal of Adhesion, 1969. 1(4): p. 290298.

4. Evans, A.G., A method for evaluating the time-dependent failure characteristics of brittle materials - and its application to polycrystalline alumina. Journal of Materials Science, 1972. 7(10): p. 1137-1146.

5. Williams, D.P. and A.G. Evans, A simple method for studying slow crack growth. Journal of Testing and Evaluation, 1973. 1: p. 264-270.

6. Shyam, A. and E. Lara-Curzio, The double-torsion testing technique for determination of fracture toughness and slow crack growth behavior of materials: A review. Journal of Materials Science, 2006. 41(13): p. 4093-4104.

7. Tait, R.B., P.R. Fry, and G.G. Garrett, Review and evaluation of the double-torsion technique for fracture toughness and fatigue testing of brittle materials. Experimental Mechanics, 1987. 27(1): p. 14-22.

8. Ebrahimi, M.E., J. Chevalier, and G. Fantozzi, Slow crack-growth behavior of alumina ceramics. Journal of Materials Research, 1999. 15: p. 142-147. 
9. Salem, J.A., M. Radovic, E. Lara-Curzio, and G. Nelson. Fracture toughness of thin plates by the double-torsion test method. 2007: American Ceramic Society.

10. Baskaran, S., S.B. Bhaduri, and D.P.H. Hasselman, Effect of crystallites on subcritical crack growth and strain-rate sensitivity of strength of cordierite glass-ceramics. Journal of the American Ceramic Society, 1985. 68(3): p. 112-119.

11. Chevalier, J., A.H. De Aza, L. Gremillard, R. Zenati, and G. Fantozzi, Slow Crack Growth in Zirconia Ceramics: From the Single Crystal to the Composites. Materials Engineering, 2001. 12(2): p. 159-178.

12. Chevalier, J., M. Saadaoui, C. Olagnon, and G. Fantozzi, Double-torsion testing a $3 Y$ TZP ceramic. Ceramics International, 1996. 22(2): p. 171-177.

13. Ferber, M.K. and S.D. Brown, Subcritical crack growth in dense alumina exposed to physiological media. Journal of the American Ceramic Society, 1980. 63(7-8): p. 424429.

14. Fuller Jr, E.R., ed. An Evaluation of Double-Torsion Testing-Analysis. Fracture Mechanics Applied to Brittle Materials, ASTM STP 678, ed. S.W. Freiman. 1979, American Society for Testing and Materials. 3-18.

15. Pletka, B.J. and S.M. Wiederhorn, A comparison of failure predictions by strength and fracture mechanics techniques. Journal of Materials Science, 1982. 17(5): p. 1247-1268.

16. Sano, O., A revision of the double-torsion technique for brittle materials. Journal of Materials Science, 1988. 23(7): p. 2505-2511.

17. Vekinis, G., M.F. Ashby, and P.W.R. Beaumont, R-curve behaviour of Al2O3 ceramics. Acta metallurgica et Materialia, 1990. 38(6): p. 1151-1162.

18. Leevers, P.S., Large deflection analysis of the double torsion test. Journal of materials science letters, 1986. 5(2): p. 191-192.

19. Ciccotti, M., G. Gonzato, and F. Mulargia, The double torsion loading configuration for fracture propagation: an improved methodology for the load-relaxation at constant displacement. International Journal of Rock Mechanics and Mining Sciences, 2000. 37(7): p. 1103-1113.

20. Ciccotti, M., N. Negri, G. Gonzato, and F. Mulargia, Practical application of an improved methodology for the double torsion load relaxation method. International Journal of Rock Mechanics and Mining Sciences, 2001. 38(4): p. 569-576.

21. Pabst, R.F. and J. Weick, Double-torsion measurements with and without a guiding notch. Journal of Materials Science, 1981. 16(3): p. 836-838.

22. Virkar, A.V. and R.S. Gordon, Crack front profiles in double-torsion specimens. Journal of the American Ceramic Society, 1975. 58(11-12): p. 536-37.

23. Pollet, J.C. and S.J. Burns, Crack velocity correction factor for the crack-front shape in double-torsion specimens. J. Am. Ceram. Soc, 1979. 62(7): p. 426-427.

24. Biswas, D.R. and V.K. Pujari, Verification of the Double-Torsion Equation by Using Different Thickness Samples of a Machinable Glass-Ceramic. Journal of the American Ceramic Society, 2006. 64(7).

25. Leevers, P.S., Crack-front shape effects in the double torsion test. Journal of Materials Science, 1982. 17(9): p. 2469-2480.

26. Stalder, B. and H.H. Kausch, Some geometrical observations on crack front profiles in PMMA double torsion specimens. Journal of Materials Science, 1982. 17(9): p. 2481-2485.

27. Hine, P.J., R.A. Duckett, and I.M. Ward, A double-torsion study of the fracture of polyethersulphone. Journal of Materials Science, 1984. 19(11): p. 3796-3805. 
28. Madjoubi, M.A., M. Hamidouche, N. Bouaouadja, J. Chevalier, and G. Fantozzi, Experimental evaluation of the double torsion analysis on soda-lime glass. Journal of Materials Science, 2007. 42(18): p. 7872-7881.

29. Ciccotti, M., Realistic finite-element model for the double-torsion loading configuration. J. Am. Ceram. Soc., 2000. 83(11): p. 2737-2744.

30. Kourtesis, G., G.M. Renwick, A.C. Fischer-Cripps, and M.V. Swain, Mechanical property characterization of a number of polymers using uniaxial compression and spherical tipped indentation tests. Journal of Materials Science, 1997. 32(17): p. 4493-4500.

31. ABAQUS, User's Manual. 2008: ABAQUS Inc., Prvidence, Rhode Island, Version 6.9 .

32. Trantina, G.G., Stress Analysis of the double-torsion specimen. Journal of the American Ceramic Society, 2006. 60(7-8): p. 338-341.

33. Kamp, N., M.R. Parry, K.D. Singh, and I. Sinclair, Analytical and finite element modelling of roughness induced crack closure. Acta Materialia, 2004. 52(2): p. 343353.

34. Suresh, S. and R.O. Ritchie, A geometric model for fatigue crack closure induced by fracture surface roughness. Metallurgical and Materials Transactions A, 1982. 13(9): p. 1627-1631.

35. Wasen, J., K. Hamberg, and B. Karlsson, The influence of grain size and fracture surface geometry on the near-threshold fatigue crack growth in ferritic steels. Materials Science and Engineering: A, 1988. 102(2): p. 217-226.

36. Li, F.Z., C.F. Shih, and A. Needleman, A comparison of methods for calculating energy release rates. Engineering Fracture Mechanics, 1985. 21(2): p. 405-421.

37. Sutton, M.A., W.J. Wolters, W.H. Peters, W.F. Ranson, and S.R. McNeill, Determination of displacements using an improved digital correlation method. Image and Vision Computing, 1983. 1(3): p. 133-139.

38. McKenna, S.P. and W.R. McGillis, Performance of digital image velocimetry processing techniques. Experiments in fluids, 2002. 32(1): p. 106-115.

39. Da Fonseca, J.Q., P.M. Mummery, and P.J. Withers, Full-field strain mapping by optical correlation of micrographs acquired during deformation. Journal of microscopy, 2005. 218(1): p. 9-21.

40. DaVis, User's Manual. 2009, Gottingen: LaVision GmbH,.

41. Sutton, M.A., S.R. McNeill, J.D. Helm, and Y.J. Chao, Advances in two-dimensional and three-dimensional computer cision. Topics in Applied Physics, 2000. 77: p. 323372.

42. Riccò, T., R. Frassine, and A. Pavan, Problems in fracture mechanics characterization of rubber-modified glassy polymers, using double torsion. Journal of Materials Science, 1990. 25(3): p. 1517-1521.

43. Salem, J., M. Radovic, E. Lara-Curzio, and G. Nelson. Fracture toughness of thin plates by the double-torsion test method. 2007: American Ceramic Society.

44. Albuquerque, M.C.F. and J.A. Rodrigues, Characteristics of the double-torsion test to determine the R-curve of ceramic materials. Materials Research, 2006. 9: p. 361-368. 


\section{LIST OF TABLES:}

Table 1: Specimen dimensions and ratios considered for the experimental evaluation

Table 2: Correction factors for the considered specimen configurations

Table 3: Compliance relationship data for all specimen configurations considered. Two starter notch length configurations of 20 and $40 \mathrm{~mm}$ were considered for the experimentally determined compliance

Table 4: $\quad G_{I c}$ and equivalent $K$ for all specimen configurations

\section{LIST OF FIGURES:}

Figure 1: Schematic of the Double Torsion (DT) specimen geometry. The curved crack front profile is defined by the difference in crack extensions as $\Delta a$.

Figure 2: Schematic of the load configuration and the large deflection error caused by the rotation of the loading points. A correction is provided by Leevers as $w_{m}{ }^{L D C}[18]$.

Figure 3a: Finite Element mesh for the $3 W: W: 0.08 W$ geometry with a crack front inclination of $c=0$. Model represents the full DT geometry.

Figure 3b: Finite Element mesh for the $2.7 W: W: 0.11 W$ geometry with a crack front inclination of $c=4$. Shown is half the DT geometry with maximum principle stress contours.

Figure 4: Percentage error in the calculation of $K_{I}$ for three specimen thicknesses when using Eq. 2. All specimens have the same loading configuration shown in Figure 2.

Figure 5: Comparison between the various found compliance relationships for the $2.7 \mathrm{~W}$ : $W: 0.11 W$ geometry.

Figure 6: Out-of-plane deformations of on the specimen surface at crack length $a=76 \mathrm{~mm}$ obtained through the DIC analysis and the relative load point deflections at the crack tip. Shown are the Abaqus and DIC obtained surface displacements.

Figure 7: Comparison of crack length independency. Plotted are Evans' model, Evans' model with LDC, Chevalier's model Ciccotti's model for specimen dimensions $2.7 W: W: 0.11 W$. A crack length independent setup is identified by a horizontal fitted line. 
Figure 8: Comparison of crack length independency obtained from the FE analysis. Plotted are specimen dimensions $2.7 \mathrm{~W}: \mathrm{W}: 0.11 \mathrm{~W}$ and $3 \mathrm{~W}: \mathrm{W}: 0.08 \mathrm{~W}$.

Figure 9: Investigation of the crack length independency for four identical specimen configurations. Shown are: i) a pre-cracked specimen with "skew" crack propagation, ii) a pre-cracked specimen with symmetrical crack propagation, iii) no pre-crack with symmetrical crack propagation and iv) no pre-crack with "skew" crack propagation. A crack length independent setup is identified by a horizontal fitted line.

Figure 10: SIF profile for mode I and mode II through thickness $\mathrm{r} / d$ at crack length $a=37.5$ $\mathrm{mm}$ and $112.5 \mathrm{~mm} . \mathrm{r} / \mathrm{d}=1$ at upper tensile surface.

Figure 11: Illustration of the direct method to determine $G_{I c}$ from the measured compliance at several loading and unloading curves.

Figure 12: VK curves obtained by successive relaxations using 1) Evans' methodology with specimen ratio $3 \mathrm{~W}: \mathrm{W}: 0.08 \mathrm{~W}, 2$ ) Chevalier's methodology using $3 \mathrm{~W}: \mathrm{W}: 0.08 \mathrm{~W}$ specimen geometry and 3) Ciccotti's methodology using $2.7 \mathrm{~W}: \mathrm{W}: 0.11 \mathrm{~W}$ specimen geometry.

Figure 13: Relative scatter in VK relationship data as a function of $\log (B)$ (y-axis intercept).

Figure 14: Relationship of $D_{E}$ and $a_{\text {off. }}$ A $a_{o f f}<1 / 8 W$ limit was established.

Figure 15: Effect of misalignment on $K_{\text {eff }}$ shown on left $y$-axis and the contributions of $K_{I}$, $K_{I I}$ and $K_{I I I}$ on $K_{\text {eff }}$ on right $y$-axis. 


\section{TABLES:}

Table 1:

\begin{tabular}{|cc|c|ccc|l|}
\hline \multicolumn{2}{|c|}{$\begin{array}{c}\text { Geometry }(L: W: d) \\
\text { dimensions }(\mathrm{mm})\end{array}$} & $\begin{array}{c}\text { notch } a_{n} \\
(\mathrm{~mm})\end{array}$ & \multicolumn{3}{|c|}{ Used for } & recommended by \\
\hline \multirow{2}{*}{$150: 50: 4$} & $3.0 W: W: 0.08 W$ & 20 & $\mathrm{X}$ & $\mathrm{FE}$ & $\mathrm{DIC}$ & X \\
& $3.0 W: W: 0.10 W$ & 20 & $\mathrm{X}$ & & Chevalier [12] \\
\hline \multirow{2}{*}{$150: 50: 5$} & 40 & $\mathrm{X}$ & & & Tait [7] \\
& $2.7 W: W: 0.11 W$ & 20 & $\mathrm{X}$ & $\mathrm{X}$ & $\mathrm{X}$ & \multirow{2}{*}{ Ciccotti $[19,20]$} \\
\hline \multirow{2}{*}{$135: 50: 5.5$} & 40 & $\mathrm{X}$ & & & \\
\hline
\end{tabular}

Table 2:

\begin{tabular}{|c|c|c|c|c|c|c|c|c|c|c|c|c|c|c|}
\hline $\begin{array}{c}\text { Geometry } \\
\text { configuratio }\end{array}$ & & $\begin{array}{l}\text { Thickness } \\
\text { correction }\end{array}$ & $\begin{array}{l}\text { crack } \\
\text { front }\end{array}$ & Leevers & Che & lier & & tti et & $\varphi(a)$ & $r \xi(a$ & $=X_{1} a$ & $+X_{2} a$ & $+X_{3} a$ & $X_{4}$ \\
\hline & & & & & & & & & & & & & & \\
\hline$(L: W: d)$ & $a_{n}$ & $\psi(\tau)$ & $\phi(\alpha, d)$ & $S$ & $m$ & $k$ & $\begin{array}{c}X_{1} \\
10^{-8} \\
\end{array}$ & $\begin{array}{c}X_{2} \\
10^{-6} \\
\end{array}$ & $\begin{array}{c}X_{3} \\
10^{-4} \\
\end{array}$ & $X_{4}$ & $\begin{array}{c}X_{1} \\
10^{-6} \\
\end{array}$ & $\begin{array}{c}X_{2} \\
10^{-4} \\
\end{array}$ & $\begin{array}{c}X_{3} \\
10^{-2} \\
\end{array}$ & $X_{4}$ \\
\hline & 20 & & & 1.89 & 3 & 47 & & & & & & & & \\
\hline $3 W: 1: 0.08 W$ & 40 & 0.861 & 0.143 & 1.89 & 3 & 47 & & & & & & & & \\
\hline & 20 & & & 1.83 & 2 & 47 & & & & & & & & \\
\hline $3 W: 1: 0.10 V W$ & 40 & $0.8 / 4$ & 0.143 & 1.83 & 2 & 47 & & & & & & & & \\
\hline & 20 & & & 1.74 & 1.2 & 48 & -7.8 & 0.12 & 9.31 & 0.73 & 1.82 & -5.1 & 4.75 & -0.47 \\
\hline 2.100 .1 .0 .110 & 40 & 0.002 & $0.17 \mathrm{~J}$ & 1.74 & 1.2 & 48 & -2.5 & -2.7 & 0.23 & 0.67 & 1.91 & -5.4 & 5.04 & -0.57 \\
\hline
\end{tabular}

Table 3:

\begin{tabular}{|l|cc|c|cccc|}
\hline \multirow{2}{*}{$\begin{array}{l}\text { Geometry } \\
(L: W: d)\end{array}$} & \multicolumn{2}{|c|}{$\begin{array}{c}\text { Compliance } \\
\text { constants }\end{array}$} & $\begin{array}{c}\text { Compliance } \\
\text { constants }\end{array}$ & \multicolumn{3}{|c|}{ Compliance constants (Finite Element) } \\
\cline { 5 - 8 } & (Experimental) & (Analytical) & \multicolumn{3}{|c|}{ Crack front inclination } \\
& $B_{E}$ & $D_{E}$ & $B_{A}$ & $B_{F E}$ & $D_{F E}$ & $B_{F E}$ & \multicolumn{2}{c|}{$D_{F E}$} \\
& $\cdot 10^{-5}$ & $\cdot 10^{-3}$ & $\cdot 10^{-5}$ & $\cdot 10^{-5}$ & $\cdot 10^{-3}$ & $\cdot 10^{-5}$ & $\cdot 10^{-3}$ \\
\hline $3 \mathrm{~W}: \mathrm{W}: 0.08 \mathrm{~W}$ & 7.5 & 3.0 & 7.86 & 7.90 & 2.17 & 7.63 & 2.67 \\
$3 \mathrm{~W}: \mathrm{W}: 0.10 \mathrm{~W}$ & 9.7 & 1.8 & 10.12 & - & - & - & - \\
$3 \mathrm{~W}: \mathrm{W}: 0.11 \mathrm{~W}$ & 12.0 & 1.0 & 13.02 & 13.11 & 0.71 & 12.21 & 0.92 \\
\hline
\end{tabular}


Table 4:

\begin{tabular}{|c|c|c|c|c|}
\hline $\begin{array}{l}\text { Geometry } \\
(L: W: d)\end{array}$ & $3 W: W: 0.8 W$ & $\begin{array}{l}G_{I c}(M P a . m m) \\
3 W: \mathrm{W}: 0.10 W\end{array}$ & $2.7 W: W: 0.11 W$ & $\begin{array}{c}\text { equivalent } K_{I c}(\mathrm{MPa} \sqrt{\mathrm{m}}) \\
3 W: \mathrm{W}: 0.8 W\end{array}$ \\
\hline $\begin{array}{l}G_{I}^{E} \\
G_{I}^{E+L D C}\end{array}$ & $\begin{array}{l}472 \pm 50 \\
421 \pm 15\end{array}$ & $\begin{array}{l}468 \pm 56 \\
422 \pm 30\end{array}$ & $\begin{array}{l}471 \pm 70 \\
419 \pm 50\end{array}$ & $\begin{array}{l}1.64 \pm 0.5 \\
1.48 \pm 0.2\end{array}$ \\
\hline $\begin{array}{l}G_{I}^{L} \\
G_{I}^{\mathrm{L}+L D C}\end{array}$ & $\begin{array}{l}973 \pm 40 \\
879 \pm 20\end{array}$ & $\begin{array}{l}953 \pm 44 \\
845 \pm 30\end{array}$ & $\begin{array}{l}923 \pm 50 \\
822 \pm 45\end{array}$ & $\begin{array}{l}2.21 \pm 0.5 \\
2.09 \pm 0.3\end{array}$ \\
\hline $\begin{array}{l}G_{I}^{C h} \\
G_{I}^{C h+L D C}\end{array}$ & $\begin{array}{l}484 \pm 18 \\
436 \pm 10 \\
\end{array}$ & $\begin{array}{l}488 \pm 20 \\
432 \pm 11 \\
\end{array}$ & $\begin{array}{l}481 \pm 25 \\
437 \pm 12 \\
\end{array}$ & $\begin{array}{l}1.70 \pm 0.3 \\
1.53 \pm 0.2 \\
\end{array}$ \\
\hline $\begin{array}{l}G_{I}^{C i} \\
G_{I}^{C i+L D C}\end{array}$ & - & - & $\begin{array}{l}426 \pm 19 \\
387 \pm 8\end{array}$ & $\begin{array}{l}1.50 \pm 0.2 \\
1.36 \pm 0.2\end{array}$ \\
\hline$G_{I}^{P}$ & $419 \pm 9$ & $421 \pm 10$ & $420 \pm 10$ & $1.48 \pm 0.2$ \\
\hline$G_{I}^{F E}$ & 419 & & 418 & 1.48 \\
\hline
\end{tabular}

Table 5

\begin{tabular}{|c|c|c|c|}
\hline Analysis method & $\begin{array}{l}\text { Geometry } \\
(L: W: d)\end{array}$ & $\begin{array}{c}\text { sub critical } \\
\text { crack growth exponent } \\
n\end{array}$ & $\begin{array}{c}\text { y-axis intercept } \\
\text { constant } \\
\log (B)\end{array}$ \\
\hline \multirow{2}{*}{ Evans' method } & $2.7 W: W: 0.11 W$ & $32 \pm 4$ & $2.2^{-7}$ \\
\hline & $3 W: W: 0.08 W$ & $33 \pm 3$ & $9.4^{-7}$ \\
\hline \multirow{2}{*}{ Chevalier's correction } & $2.7 W: W: 0.11 W$ & $35 \pm 3$ & $5.8^{-7}$ \\
\hline & $3 W: W: 0.08 W$ & $35 \pm 2$ & $6.2^{-7}$ \\
\hline Ciccotti's correction & $2.7 W: W: 0.11 W$ & $36 \pm 3$ & $1.8^{-7}$ \\
\hline
\end{tabular}

